\section{Climatic Means and Normals-A Statement of the American Association of State Climatologists (AASC)}

\author{
Kenneth E. Kunkel, ${ }^{*}$ and Arnold Court ${ }^{+}$
}

\section{Introduction}

The members of the American Association of State Climatologists (AASC) $)^{1}$ work daily at the interface between the meteorological/climatological profession and the many climate-sensitive aspects of our society. As a result, we are keenly aware of the limitations of standard climatic information in truly addressing societal needs. Blind use of such information may be misleading for certain applications. For example, utility rates are based in part on assumptions about climatic conditions in the near future. The 30-yr normals are usually used as the best predictor of the future climate when research in fact suggests that they are not optimum predictors. Analysis of the situation by the applied climatologist will usually avoid such misuse. However, it is also useful to review periodically the suitability of standard climatic information for general use. Many general uses are for planning purposes in which long-term averages are in fact used as predictors of future climate. For example, rain insurance rates for fairs, tournaments, and concerts are based on the most recent climatic "normals." Therefore, the AASC recently conducted a review of work concerning the applicability of climatic averages. As a result of this review, the AASC made a number of recommendations to the National Climatic Data Center (NCDC) regarding possible changes to publications of climatic statistics. These recommendations

\footnotetext{
* Midwestern Climate Center, Illinois State Water Survey, Climate and Meteorology Section, Champaign, IL 61820.

+ Department of Geography, California State University-Northridge, Northridge, CA 91330.
}

\footnotetext{
1. A brief description and history of the AASC is given by Changnon (1981). The current membership of the AASC consists of 45 state climatologists and approximately 80 other active professional climatologists, who are associate members.
}

(C) 1990 American Meteorological Society address the following questions:

1) Are climatic averages for other than the traditional $30-y r$ periods more appropriate for general use?

2) Is the use of the word "normal" to describe 30yr means inappropriate and misleading to nonclimatologists?

3) What is the relative importance of other climatic descriptors, such as median, standard deviation, percentiles, etc.?

Although the following statement is directed primarily to NCDC, we hope that other AMS members involved in applied climatological activities will find it informative.

\section{AASC statement on climatic means and normals ${ }^{2}$}

\section{a. Meaning of "normal"}

The term "normal" applied to climatic statistics has developed a specific meaning in climatology: a mean over $30 \mathrm{yr}$ beginning in the first year of a decade (e.g., 1951-80). However, to many others, the term "normal" may imply that climate is stable and unchanging and that over a long enough period temperature and precipitation values will be evenly distributed about the normal. The "normal" in this case represents a standard toward which climate statistics ought to converge.

Since a time series of climate variables can be $d y$ namic and nonstationary, such an expectation has no basis. Indeed, an 1880-1980 time series of temperature for the Northern Hemisphere shows a warming during the first 50 or so years, followed by a slight cooling trend thereafter.

Thus, climatologists may question whether the term "normal" should remain in our terminology. Has the term been overused and misused in the past, has it come to mean "stationary" to the uninformed

\footnotetext{
${ }^{2}$ This statement was approved by the members of the AASC in attendance at the 1989 annual meeting (8-9 July 1989, Bar Harbor, Maine).
} 
user, and has it therefore lost its specificity and credibility? Indeed, the term "normal" has come under criticism in the past (Landsberg 1947). There is no a priori reason for a 30-yr mean to be a standard of any particular physical significance; they are not optimum for all applications. For example, climate fluctuations occur on all time scales and 30-yr means have no inherent stability.

An additional source of confusion to the nonclimatologist is that "normal" also refers to a Gaussian probability distribution. This may imply that climatic variables follow a Gaussian distribution, which is certainly not the case with many variables, such as precipitation.

On the other hand, the word "normal" is deeply ingrained in the language of users of climatic data (e.g., "departure from normal"). Replacement of the word "normal" will almost certainly bring about confusion among United States users and the general public. The cost of changing may not be worth the gain in linguistic accuracy. Therefore, a cautious approach is to retain the word "normal" for the present.

Until well into the twentieth century, most climatic summaries were simple arithmetic averages for an entire period of record (POR), regardless of when that occurred; more attention was given to the length of record (LOR) - the longer the better. All observations, from whatever instruments and averaged by any method, from varying exposures and locations around a given place, were averaged to describe climate.

Growing realization that climate varies over scales from millions of years down to centuries and decades led the International Meteorological Organization (IMO) to adopt the recommendation of its climatology commission, meeting in Warsaw in 1933, that such phenomena be studied as changes in successive 30-yr climatic "normals." These were defined as arithmetic averages over 30-yr periods beginning in the first year of a decade (e.g., 1901-30, 1911-40, etc.). Member nations were urged to compute and publish such "normals" for all climatic elements, and use the entire record only for extremes: wettest hour, day, year; coldest and hottest temperatures; longest period without direct sunshine, etc. During the ensuing half-century, such "normals" were adopted by most meteorological services, although the United States computes them only for temperature, rainfall, and pressure, retaining POR values for cloudiness, windspeed, thunderstorms, etc.

The 30-yr period was a compromise estimate of the duration of reliable human memory, and of the LOR available for enough places worldwide. Some members wanted 11 (solar cycle), or 20 or $25 \mathrm{yr}$, because more stations could have such "normals."
Others urged the 35-yr "Brückner cycle," and still others a $50-y r$ period. The $30-y r$ averaging period was adopted primarily to monitor climatic change.

\section{b. Normals as predictors}

In many applications, normals are used as predictors of the future climate. For this, the adopted 30-yr averages have been found to have no special predictive properties. In fact, to predict the coming year's climate, 30-yr means have been found to have less predictive skill than other period means (Beaumont 1957; Enger 1959; Court 1967-68; Lamb and Changnon 1981).

One perhaps insuperable difficulty in assessing the predictive abilities of various climate means is the lack of any truly objective measure of superiority or utility. Minimizing the mean-square error is widely used but it may not be related to the actual economic loss from a bad prediction. For example, an error of $2^{\circ}$ in a forecast does not generally result in four times the economic loss from an error of $1^{\circ}$. Until economic-loss functions for climatic prediction errors are developed, comparison of the predictive abilities of various climatic averages will remain theoretical.

The choice of an alternate averaging period for use as a predictor is complicated by differences in published results. Beaumont (1957) found that a 15-20$\mathrm{yr}$ average produced the smallest root-mean-square error. Enger (1959) similarly suggests a 15-25-yr average. By contrast, Court (1968) suggests an odd number of years in the range of 7-15 yr. Lamb and Changnon (1981) suggest a 5-yr average, although their results were based only on Illinois data averaged over periods of 5, 10, 15, 20, 25, and $30 \mathrm{yr}$. Dixon and Shulman (1984) found widely varying results depending on the criterion used to judge skill. Sabin and Shulman (1985) suggest a 35-40-yr average although they found relatively little difference for shorter period averages down to $10 \mathrm{yr}$. Their results were also dependent on whether a station relocation had occurred in the record. (The problems of contamination of the climatic record by station moves are serious and complex, and beyond the scope of this statement). To further complicate this situation, Court (1968) found that the optimum average to predict $k$ years ahead was $k$ years shorter than for next year. But Easterling et al. (1989) found that, while an $11-y r$ average was preferable as a predictor of the coming year's climate, a 19-yr average was preferable for $2,3,4$, or 5 years ahead. This study was also limited to Illinois but considered more stations than the Lamb and Changnon study.

These differences create a problem since a base period other than $30 \mathrm{yr}$ requires a clear rationale. Yet, published results agree only that a base period of 30 
$\mathrm{yr}$ is not optimum, but do not agree what should replace it. An important operational consideration is that publications which include climatic averages are not likely to be updated often and will be used for several years after appearance. Short-term averages (e.g., $5 \mathrm{yr}$ ) would be inappropriate as predictors for more than 1 or 2 years immediately following the averaging period. Therefore, the realities of climatic publication schedules and use probably preclude the adoption of such short-term averages and favor a somewhat longer averaging period. An additional consideration is that several studies found optimum results for averaging periods around 10 to $20 \mathrm{yr}$.

\section{c. Normals as a measure of central tendency}

A final point related to $30-y r$ "normals" is that the mean in many cases is not the best measure of central tendency, especially for non-Gaussian probability distributions. In dry climates the monthly or annual means of precipitation are strongly influenced by the few wet years. For instance, in California less than $25 \%$ of all Julys are wetter than the mean (Slusser 1968). This goes against the popular perception that half of all years should be less than average, the other half more than average. This suggests that in many instances the median is a superior measure of central tendency, since it is the exact middle value. But because the uncertainty of the estimate of the median is greater than that of the mean for the same time series, the median may be desirable only for nonGaussian time series. The calculation of the median is straightforward when an odd number of years is used. This is a consideration which influences the choice of alternative averaging periods.

Guttman (1989) suggests that publication of medians in addition to averages may have value to users. Our recommendations are stronger in that we consider the median preferable for some climatic elements; it should replace the arithmetic average in situations where both cannot be included. This is in line with the recommendations of a committee of the American Geophysical Union (Church et al. 1941) who stated, "After carefully weighing the advantages and disadvantages of the median versus the arithmetic average, the committee unanimously recommends that in the future, at least for hydrologic studies, the expression of normals of precipitation be defined by the median."

\section{d. Year-to-year variability}

In addition to the central tendency itself, an essential element of descriptive climatology is the variability about the central tendency. In fact, year-to-year variability is usually much larger than long-term changes in the mean or median. There are several possible measures of this variability. For Gaussian or quasiGaussian probability distributions, the standard deviation is a common measure; for non-Gaussian distributions, the mean absolute deviation is often used. Values at several points on the cumulative probability curve are of greater detail and therefore more utility. This has been done for precipitation in at least one publication (Houghton 1985) where the 10 and 90 percentiles for precipitation are presented. These particular percentile values also represent the National Weather Service's thresholds for "much below" and "much above" categories.

\section{e. Recommendations}

Based on the above discussion, the AASC makes the following recommendations regarding future publications of climate statistics:

1) The term "normal" should be retained to describe 30-yr climatic means, for continuity and to comply with WMO standards for monthly and annual climate descriptions. The 30-yr means should continue to be included.

2) For averaging periods other than $30 \mathrm{yr}$, the median should be adopted as a better measure of central tendency for certain climatic variables which in many locations follow a non-Gaussian distribution (e.g., total precipitation, total snowfall, etc.). The mean should be used for other climatic variables such as temperature whose distribution is usually quasi-Gaussian.

3) Inclusion of additional averaging periods other than $30 \mathrm{yr}$ in published statistics would provide flexibility in responding to climatic needs. The AASC suggests inclusion of 11- and 21-yr periods in published statistics. These particular values reflect the clustering of research results around 10 to $20 \mathrm{yr}$; an odd value is used to simplify the determination of the median for non-Gaussian distributions. In addition, these values are intuitively attractive, representing one or two decadal periods (e.g., a "decade" of 19902000 covers $11 \mathrm{yr}$ ).

4) A measure of variability should be included along with the mean and/or median: 10 and 90 percentiles for non-Gaussian climatic data distributions, the standard deviation for quasi-Gaussian distributions.

5) For all climatic elements a measure of variability is of greater priority for inclusion in limited publication space than are the 11and $21-y r$ averaging periods suggested in recommendation 3 .

6) Extremes of climatic variables should be cited for the entire period of homogeneous record (e.g., constant instrument siting, instrument exposure, and observational practices).

\section{References}

Beaumont, R. T. 1957. A criterion for selection of length of record for a moving arithmetic mean for hydrologic data. Trans. Amer. Geophysl. Union 38: 198-000

Changnon, S. A. 1981. The American Association of State Climatologists. Bull. Amer. Meteor. Soc. 62: 620-622.

Church, P. E., E. L. Wells, and H. P. Boardman. 1941. Report of the Committee on median versus arithmetical average. Trans. Amer. Geophy. Union 22: 102-103.

Court, A. 1967-68. Climatic normals as predictors. Parts I-IV. Scientific Report AFCRL, Hanscom AFB, MA, Contract AF19 (628)-5176. [INTIS AD-657 358, AD-686 163, AD-672 268, 
AD-687 137, AD-687 138].

Dixon, K. W., and M. D. Shulman. 1984. A statistical evaluation of the predictive abilities of climatic averages. J. Appl. Meteor. 23: 1542-1552.

Easterling, William E., James R. Angel and Scott Kirsch. 1989. The appropriate use of climatic information in Illinois natural gas utility weather normalizations, Report of Investigation $110 \mathrm{Illi}$ nois State Water Survey, Champaign, IL.

Enger, I. 1959. Optimum length of record for climatological estimates of temperature. J. Geophys. Res. 64: 779-787.

Guttman, N. B. 1989. Statistical descriptors of climate. Bull. Amer. Meteor. Soc. 70: 602-607.

Houghton, D. D. (ed.), 1985. Handbook of Applied Meteorology.
New York: John Wiley and Sons.

Lamb, P. L., and S. A. Changnon. 1981. On the "best" temperature and precipitation normals: the Illinois situation. I. Appl. Meteor. 20: 1383-1390.

Landsberg, H. 1947. Critique of certain climatological procedures. Bull. Amer. Meteor. Soc. 28: 187-191.

Sabin, T. E., and M. D. Shulman. 1985. A statistical evaluation of the efficiency of the climatic normal as a predictor. J. Climatology 5: 63-77.

Slusser, W. F. 1968. Climatic normals as predictors, Part 3: Median vs. Mean Scientific Report. AFCRL, Hanscom AFB, MA. Contract AF19 (628)-5716 [INTIS AD-672 268]. announcements (continued from page 198)

tions, standards, codes of practice, techniques, equipment, and industrial trends. The programme will include technical visits to places of appropriate interest in and around Harare. For further information contact the Secretary, Symposium Organising Committee, P.O. Box 1921, Harare Zimbabwe, or telephone (263-4) 792268/792269.

\section{Oil Spill Conference}

Applied Science Associates, Inc. in cooperation with several other environmental and governmental groups, is planning the conference "Oil Spills: Management and Legislative Implications," 15-18 May 1990 in Newport, Rhode Island. Proposed Topics include spill response, spill contingency planning, natural resource damage assessment, modeling, fate and effects, cleanup operations, management of exploration and transport, innovations in spill control technology, managing effective spill response, and impacts of spills on legislation. Special sessions are planned on the Exxon Valdez, World Prodigy, Presidente Rivera, and Rachel $B$ spills. Abstracts received beforpe 15 March 1990 will be considered for presentation. For more information contact Malcolm L. Spaulding, Ocean Engineering, University of Rhode Island, Kingston, RI 02882, or telephone (401) 792-2537.

Notice of registration deadlines for meetings, workshops, and seminars, deadlines for submission of abstracts or papers to be presented at meetings, and deadlines for grants, proposals, awards, nominations, and fellowships must be received at least three months before deadline dates.-News Editor 